\title{
¿Spatiotemporal Characteristics of Rainfall in South China from 1967 to 2018
}

\author{
Xiaoxiong Lu, ${ }^{\mathrm{a}, \mathrm{b}}$ Qinglan Li, ${ }^{\mathrm{b}}$ Wei Zhao, ${ }^{\mathrm{b}}$ Aiguo Xiao, ${ }^{\mathrm{a}}$ GuangXin Li, ${ }^{\mathrm{b}}$ And Zifeng Yu ${ }^{\mathrm{c}}$ \\ ${ }^{\mathrm{a}}$ XiangTan University, Xiangtan, Hunan Province, China \\ ${ }^{\mathrm{b}}$ Shenzhen Institute of Advanced Technology, Chinese Academy of Sciences, Shenzhen, Guangdong Province, China \\ ${ }^{\mathrm{c}}$ Shanghai Typhoon Institute, China Meteorological Administration, Shanghai, China
}

(Manuscript received 21 August 2020, in final form 28 July 2021)

\begin{abstract}
Based on daily meteorological observation data in South China (SC) from 1967 to 2018, the spatiotemporal characteristics of the precipitation in SC over the past 52 years were studied. Only $8 \%$ of the stations showed a significant increase in annual rainfall, and there was no significant negative trend at any weather stations at a confidence level of $90 \%$. Monthly rainfall showed the most significant decreasing and increasing trends in April and November, respectively. During the entire flooding season from April to September, the monthly rainfall at the weather stations in the coastal areas showed almost no significant change. The annual rainfall gradually decreased toward the inland area with the central and coastal areas of Guangdong Province as the high-value rainfall center. By using the empirical orthogonal function decomposition method, it was found that the two main monthly rainfall modes had strong annual signals. The first modal spatial distribution was basically consistent with the average annual rainfall distribution. Based on the environmental background analysis, it was found that during the flooding season the main water vapor to SC was transported by the East Asian summer monsoon and the Indian summer monsoon. In late autumn and winter, the prevailing wind from northeastern China could not bring much water vapor to SC and led to little precipitation in these two seasons. The spatial distribution of precipitation in SC during summer was more consistent with the moisture flux divergence distribution of the bottom layer from 925 to $1000 \mathrm{hPa}$ rather than that of the layer from 700 to $1000 \mathrm{hPa}$.
\end{abstract}

KEYWORDS: Rainfall; Climate change; Water vapor; Annual variations; Trends

\section{Introduction}

In recent years, climatic variation, as a common challenge to humans, has manifested in global warming, changes in the hydrological cycle, and extreme weather events (Beniston and Stephenson 2004; Labat et al. 2004; Dore 2005; Mirza 2002; Liu 2004). Precipitation, as an essential component of the hydrological cycle, has also been affected (Dore 2005; Ding et al. 2007). The uneven spatiotemporal distribution of precipitation may cause regional drought or flooding and may impact the surface ecosystem (Ding et al. 2008; Liu et al. 2008), which makes it vital to analyze the spatiotemporal distribution of precipitation in a region.

Vulnerable to the Asian monsoon, China experienced precipitation changes in most parts of the country. Wang et al. (2015) applied the empirical orthogonal function (EOF) method to analyze the precipitation data of 1840 meteorological stations from 1960 to 2010 and found that the annual precipitation decreased in North China and the eastern part of Northwest China. However, the western part of Northwest China experienced a significant upward trend, which was similar to the conclusion of Zhang et al. (2009a). Based on gridded data, Yang and Lau (2004) examined the trends of spring and summer rainfall from 1951 to 1998 and detected positive trends for summer

¿ Denotes content that is immediately available upon publication as open access.

Corresponding author: Qinglan Li, q1.li@siat.ac.cn precipitation in central-eastern China and for spring precipitation in southeastern China. Moreover, the reasons for these trends were analyzed from annual changes in the sea surface temperature (SST). It was found that the increase in summer and spring precipitation was related to the warming trend of SSTs over the western Pacific warm pool and the Indian Ocean and the warming trend of El Niño-Southern Oscillation (ENSO)-like mode of SSTs, respectively.

The precipitation of the Yangtze River, which runs across central China from west to east, has changed over the past few decades and has attracted much attention among research communities. In the middle and lower parts of the Yangtze River, it is dominated by increasing trends of annual, summer, and winter rainfall (Zhang et al. 2009a), as well as a significant downward trend of annual rainy days and a significant upward annual precipitation intensity (Zhang et al. 2005, 2008). In particular, the increase in precipitation intensity in summer is accompanied by an increase in extreme weather events (Becker et al. 2006; Zhang et al. 2008), which leads to a higher possibility of flooding in this region. As the largest river system in South China (SC), the Pearl River basin was observed to have an increasing trend but not significant for the annual, summer, and winter rainfall, and a significant negative trend for summer and annual rainy days (Liu et al. 2009; Zhang et al. 2009b; Gemmer et al. 2011). Jiang et al. (2017) applied hourly precipitation data during April-June of 2008-15 and found that the peaks of diurnal precipitation were concentrated in the early morning and late afternoon in SC. In addition, the annual and summer extreme rainfall events demonstrated a significant increasing trend over SC since the early 1990s (Ning and Qian 2009). 


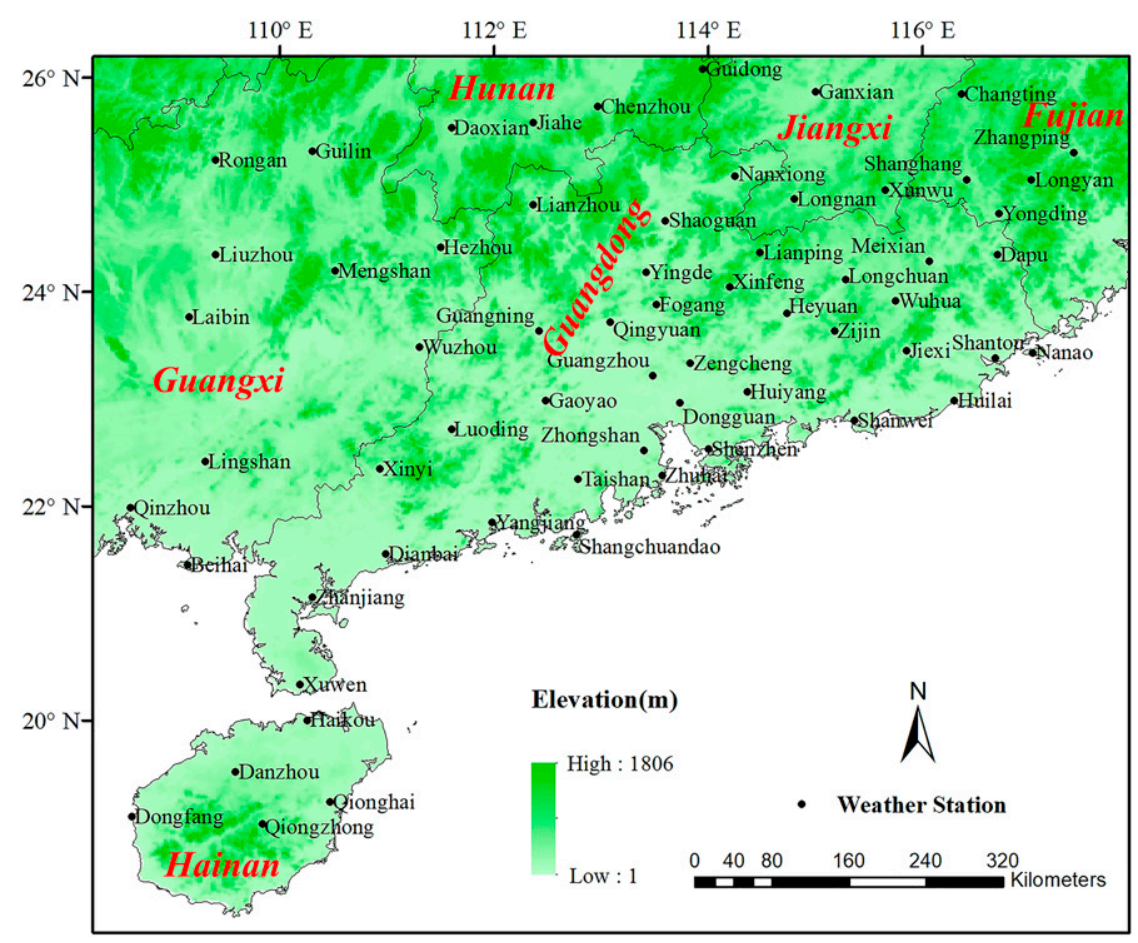

FIG. 1. Spatial distribution of the 63 basic meteorological stations in South China and the geographical features of the study area.

Influenced by the interaction of tropical and mid-high latitude weather systems, SC is the region with the most abundant precipitation in China. In addition, it is also a region with relatively rapid economic development in China. Studying the spatiotemporal distribution of rainfall is of great significance not only for understanding the regional climate system but also for water resource management and the risk assessment of drought and flood disasters in this area. Previous studies on the precipitation in SC focused more on the Pearl River basin as the study area, mainly analyzing rainfall and extreme rainfall changes for the first flooding season (April-June) and summer, and the time scale of previous studies have mainly focused on annual and seasonal scales (Zhang et al. 2009b; Fischer et al. 2011; Jiang et al. 2017). However, in addition to the first flooding season and summer, September is also a month with many typhoons making landfall in SC, bringing heavy rainfall to the region. For example, Supertyphoon Mangkhut made landfall in Guangdong on 16 September; the maximum total rainfall reached $389 \mathrm{~mm}$ and the maximum hourly rainfall intensity reached $74 \mathrm{~mm}$ in the province (Wang et al. 2019). Therefore, exploring the rainfall characteristics for every month in SC is necessary for disaster prevention in the area. Based on the annual and monthly scales, Gemmer et al. (2011) explored the trends in precipitation extremes by using daily precipitation data from 192 weather stations between 1961 and 2007 in the Zhujiang River basin. Few stations experienced trends in the precipitation indices on an annual basis. On a monthly basis, significant positive and negative trends at the $90 \%$ confidence level appeared in all months except December. They experienced the most distinct negative (positive) trends in October (January) (Gemmer et al. 2011).

Since the Gemmer et al. (2011) study, 10 years have passed. Are there any new changes in rainfall on annual and monthly scales in SC? In addition, the spatial rainfall distribution patterns in this region have seldom been revealed before. Therefore, the objectives of this study are 1) to detect the rainfall trends in SC on annual and monthly scales for a longer and updated period of time: 1967-2018; 2) to investigate the spatial and temporal distribution characteristics of the annual and monthly rainfall; 3) to explore the possible physical mechanism for the changes of the regional precipitation characteristics; and 4) to explore the dominant monthly rainfall patterns in SC.

\section{Study area and data}

The study area in this paper covers the region with latitudes ranging from $108^{\circ}$ to $118^{\circ} \mathrm{E}$ and longitudes from $18^{\circ}$ to $26^{\circ} \mathrm{N}$ in China. It is located in the southernmost part of the country, adjacent to the warm South China Sea, and includes the provinces of Hainan and Guangdong and parts of Fujian, Jiangxi, Hunan, and Guangxi. The region's climate is complex and susceptible to tropical weather systems, such as tropical cyclones, Asia summer monsoon and tropical low pressure troughs. Over the region, 63 national basic meteorological stations (NBMSs) with relatively complete daily rainfall records from 1967 to 2018 are used (see Fig. 1). The data were obtained from the National Meteorological Information 
Center of the China Meteorological Administration (National Meteorological Information Center 2019), and quality control was executed (Feng et al. 2004; Qian and Lin 2005). In particular, some missing and abnormal data are corrected according to the study by Lu et al. (2019). Moreover, to analyze and understand the pattern of the spatial distribution of precipitation in SC, National Centers for Environmental Prediction (NCEP) reanalysis data of the monthly mean wind, surface pressure, and specific humidity with a horizontal resolution of $2.5^{\circ} \times 2.5^{\circ}$ are used in this study (obtained from https:// psl.noaa.gov/data/gridded/data.ncep.reanalysis.pressure.html; Kalnay et al. 1996).

\section{Method}

\section{a. Trend analysis}

As a nonparametric statistical test method, Sen's slope estimator is widely applied to assess a changing trend by calculating the median slope of the time series (Sen 1968; Oguntunde et al. 2006). First, the slopes $p_{k}$ of all data value pairs are calculated as follows:

$$
p_{k}=\frac{x_{j}-x_{i}}{j-i} \quad k=1, \ldots, \frac{n(n-1)}{2} ; \quad 1 \leq i<j \leq n,
$$

where $n$ is the length of the time series $x_{1}, \ldots, x_{n}$ and $i$ and $j$ are the indices. Then the Sen's slope is calculated as the median of these values of $p_{k}$. The Mann-Kendall test is used to identify the significance level of the trend of time series data, such as meteorological and hydrological data (Luo et al. 2008; Liu et al. 2012). Note that although the Mann-Kendall trend test does not require a time series to obey a certain probability distribution, it requires the sequence to be independent. If there is a positive autocorrelation in the sequence, the significance of the sequence trend will be magnified (Yue and Wang 2002). To eliminate the influence of autocorrelation, this paper applies the prewhitening method to process the corresponding time series (Gocic and Trajkovic 2013; Sayemuzzaman and Jha 2014). Then, Sen's slope and Mann-Kendall test are applied to analyze the variation trend and significance level of the variation at the 63 NBMSs for annual and monthly precipitation from January 1967 to December 2018. Last, the NBMSs with significant (at the $90 \%$ confidence level) changes in annual and monthly rainfall are illustrated in the following analysis figures.

\section{b. EOF and harmonic analysis}

EOF analysis is mainly used to identify and extract the main spatial patterns (EOFs) and the corresponding independent time coefficients (TCs) from the meteorological variable field (Lorenz 1956; Hannachi et al. 2007; Wang et al. 2015). In this study, the variable field is the monthly rainfall anomaly matrix of 624 months (52 years) for the 63 NBMSs, which is obtained by subtracting each of the corresponding monthly rainfall average values of the 52 years from the monthly rainfall. Furthermore, the monthly mean TCs of the corresponding EOFs are calculated by averaging the 52-yr monthly TCs to detect the temporal variation characteristics of each EOF. The major cycle of the model's time coefficient is determined by harmonic analysis (also known as discrete power spectrum analysis), which is a statistical method using the Fourier series to identify the period of climatic and hydrological time series data (Lyons 1982; Kirkyla and Hameed 1989).

\section{c. Calculation of moisture flux and divergence}

To explore the environmental background for the regional precipitation characteristics, NECP reanalysis data is used to calculate the vertically integrated moisture flux (VIMF) and vertically integrated moisture flux divergence (VIMFD). The formulas are as follows (van Zomeren and van Delden 2007):

$$
\begin{aligned}
\mathrm{VIMF} & =\frac{1}{g} \int_{\mathrm{Pt}}^{\mathrm{Ps}} q(u, v) d p \quad \text { and } \\
\mathrm{VIMFD} & =\frac{1}{g} \int_{\mathrm{Pt}}^{\mathrm{Ps}} q\left(\frac{\partial u}{\partial x}+\frac{\partial v}{\partial y}\right) d p,
\end{aligned}
$$

where $g$ is the acceleration due to gravity, $q$ is the specific humidity, $p$ is the pressure, and $u$ and $v$ are the meridional and zonal wind vector components. In particular, when calculating the water vapor variables of the entire layer, Ps (the ground surface pressure) and Pt (the top pressure) are chosen to be 1000 and $700 \mathrm{hPa}$, respectively, as the mean sea level pressure in $\mathrm{SC}$ is close to $1000 \mathrm{hPa}$ and the water vapor transport in this region is concentrated below $700 \mathrm{hPa}$ (van Zomeren and van Delden 2007).

\section{Results and discussion}

\section{a. Characteristics of annual rainfall}

Using the rainfall data of the NBMSs, the spatial distribution of the average annual rainfall (Ave), the standard deviation (Std) for the annual rainfall, and the annual rainy days (Rds) in $\mathrm{SC}$ are calculated and illustrated in Fig. 2 by the inverse distance weighted spatial interpolation method (Gemmer et al. 2004; Goovaerts 2000). As seen from the figures, the annual rainfall in most parts of SC varies from 1400 to $2200 \mathrm{~mm}$. The highest annual rainfall area is located in the southern part of central Guangdong Province, as well as the highest Std. There are two other rainfall centers located in southeastern Hainan and southeastern Guangxi. The stations with the highest and lowest annual rainfall in SC are Yangjiang station in Guangdong and Dongfang station in Hainan, respectively. The annual rainfall on the east and west sides of Hainan differs greatly. This may be due to their different geographical locations. The southeastern side of Hainan is on the windward slope of Wuzhi Mountain (see Fig. 1), located in the middle of Hainan Island (Sun et al. 2017); however, Dongfang station is on the leeward slope of the mountain. Std for annual rainfall in the mainland generally decreases with the increased distance to the coastline, and the rainfall in coastal areas is high and fluctuates greatly year to year. When compared with Yangjiang station, the Stds in the other two rainfall centers, Qiongzhong and Qinzhou stations, are relatively small, indicating that the annual rainfall in Qiongzhong and Qinzhou is stable with high values and a slight annual rainfall fluctuation. The purple upward triangles in Fig. 2a indicate that there are significant increases in the 


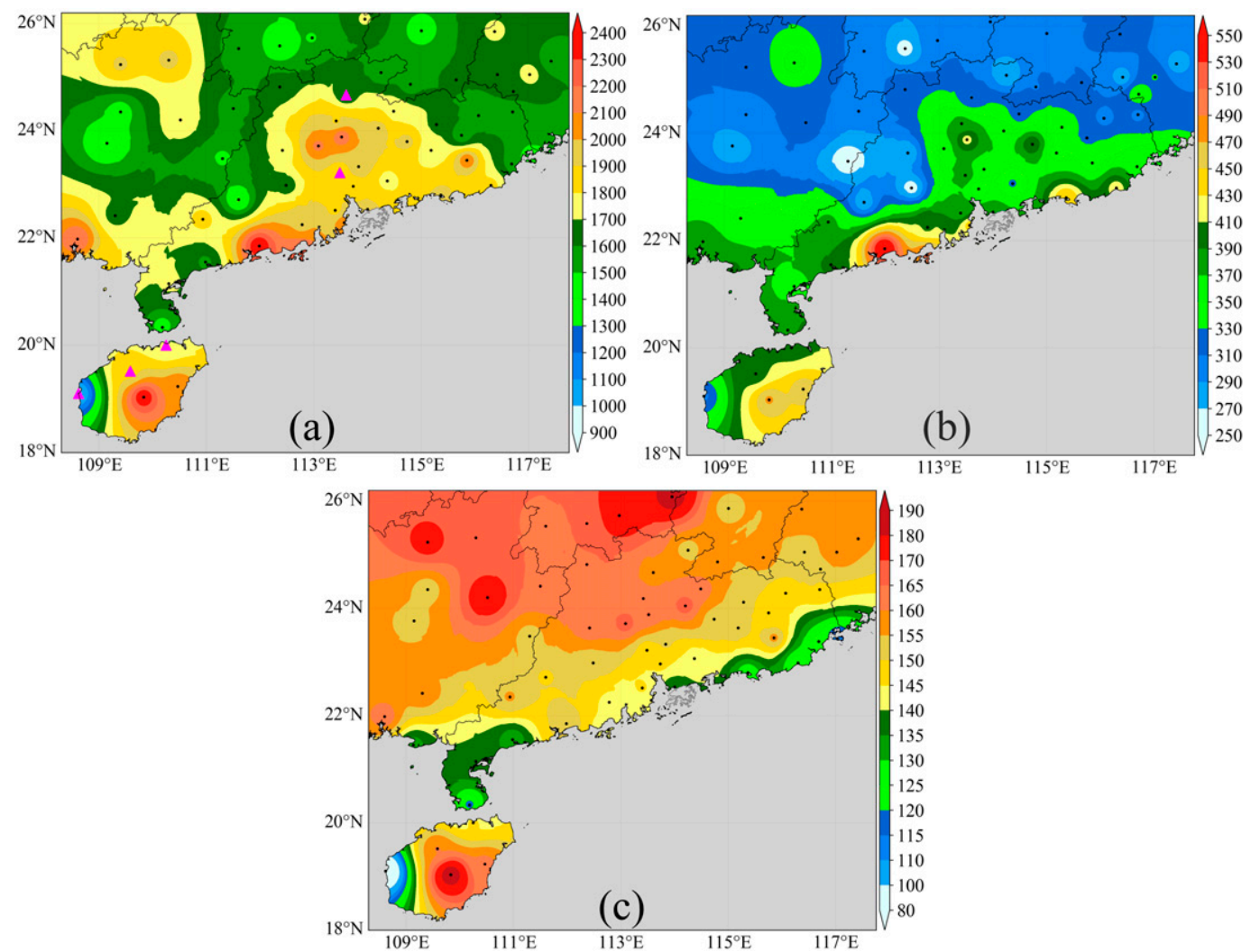

FIG. 2. The spatial distribution of the annual rainfall characteristics during 1967-2018 (a) for average annual rainfall ( $\mathrm{mm})$, (b) for the standard deviation of the average annual rainfall ( $\mathrm{mm}$ ), and (c) for annual rainy days. The purple triangles in (a) refer to the significant increase in the annual rainfall.

corresponding rainfall at the stations (the purple upward triangles indicate similar meanings hereinafter).

Figure $2 \mathrm{c}$ shows that the annual mean rainy days increase gradually from coastal areas to inland areas, which is almost opposite to the spatial distribution of the annual average rainfall over the mainland area. Combined with Figs. 2a and 2c, it is inferred that the precipitation intensity ( $\mathrm{Pi}$, computed by Ave/Rds; Zhang et al. 2008) in coastal areas is much larger than that in inland areas, which demonstrates that coastal areas are more prone to rainstorms and heavy rainfall, while inland areas are more prone to showers and moderate rainfall.

As some typical examples, Table 1 lists the detailed information of the Ave, Std, Rds, and Pi for some representative stations, including the abovementioned stations of the three highest rainfall record centers in SC during 1967-2018, as well as the Dongfang station with the lowest average annual rainfall record. Shenzhen and Guangzhou are the two most populated cities in the study area. Detailed information on the national

TABLE 1. Annual precipitation information of some stations, arranged in descending order of the weather stations' latitudes. Note: Ave refers to the annual average rainfall $(\mathrm{mm})$, Std refers to the standard deviation for the annual rainfall ( $\mathrm{mm}$ ), Rds refers to the annual rainy days (days), and Pi refers to the precipitation intensity $\left(\mathrm{mm} \mathrm{day}^{-1}\right)$. The maximum and minimum values for Ave, Std, Rds, and Pi are highlighted in boldface font.

\begin{tabular}{llccrrr}
\hline \hline \multicolumn{1}{c}{ Name } & Province & Lon $\left({ }^{\circ} \mathrm{E}\right)$ & Lat $\left({ }^{\circ} \mathrm{N}\right)$ & Ave & Std & Rds \\
\hline Chenzhou & Hunan & 112.97 & 25.73 & 1496.8 & 310.1 & 177.2 \\
Longyan & Fujian & 117.02 & 25.05 & 1756.6 & 331.1 & 160.0 \\
Wuzhou & Guangxi & 111.30 & 23.48 & 1483.5 & $\mathbf{2 5 3 . 7}$ & 153.1 \\
Guangzhou & Guangdong & 113.48 & 23.22 & 1809.6 & 384.3 & 146.9 \\
Shenzhen & Guangdong & 114.00 & 22.53 & 1920.7 & 384.0 & 135.1 \\
Qinzhou & Guangxi & 108.60 & 21.98 & 2194.0 & 381.6 & 163.1 \\
Yangjiang & Guangdong & 111.98 & 21.85 & $\mathbf{2 3 9 0 . 2}$ & $\mathbf{5 6 4 . 2}$ & 154.6 \\
Dongfang & Hainan & 108.62 & 19.10 & $\mathbf{9 9 0 . 3}$ & 307.4 & 13.2 \\
Qiongzhong & Hainan & 109.83 & 19.03 & 2384.5 & 472.7 & $\mathbf{8 2 . 7}$ \\
\hline
\end{tabular}



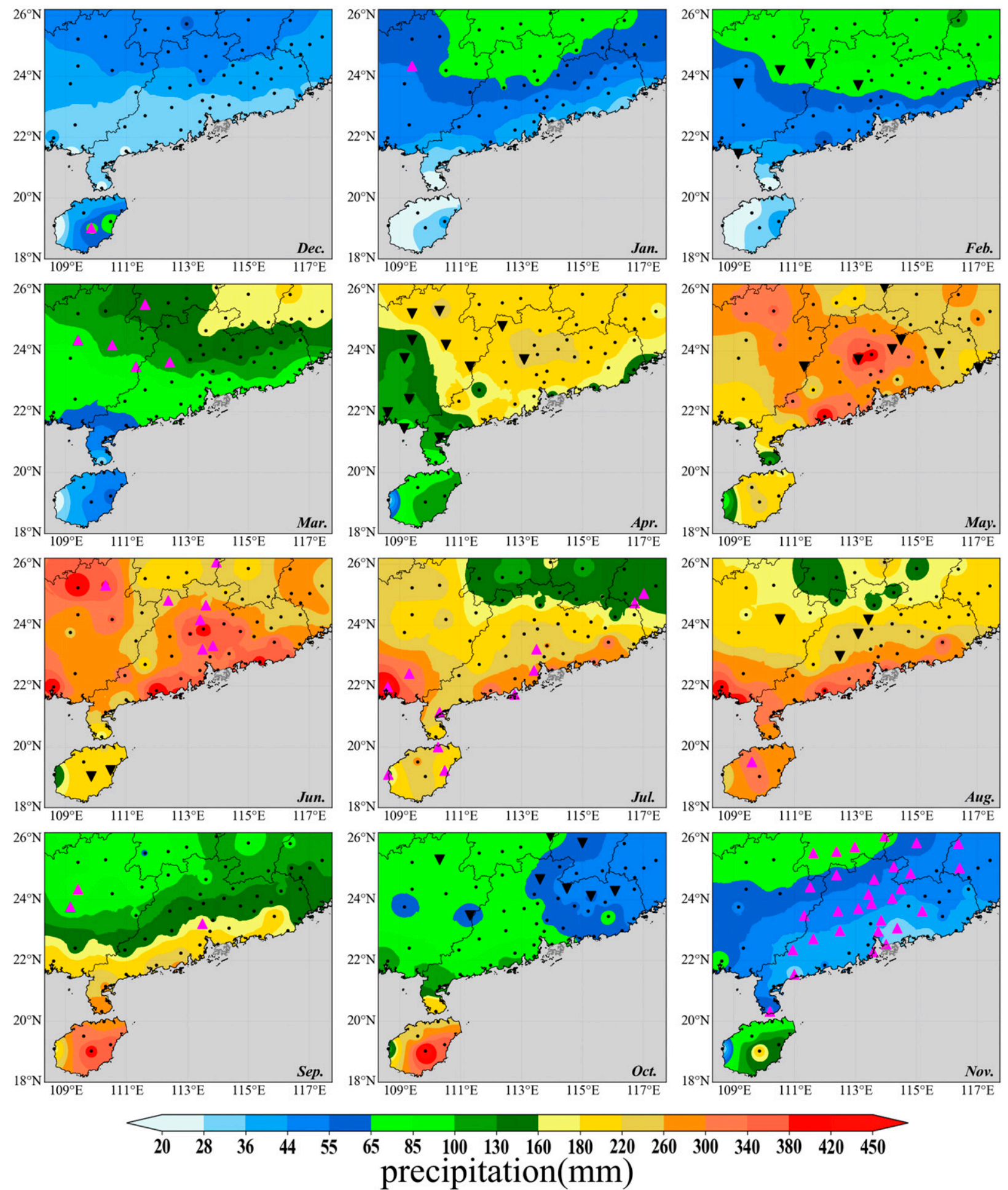

FIG. 3. The spatial distribution of the monthly average rainfall in South China during 1967-2018. The purple upward and black downward triangles respectively refer to a significant increase and decrease in monthly rainfall. 


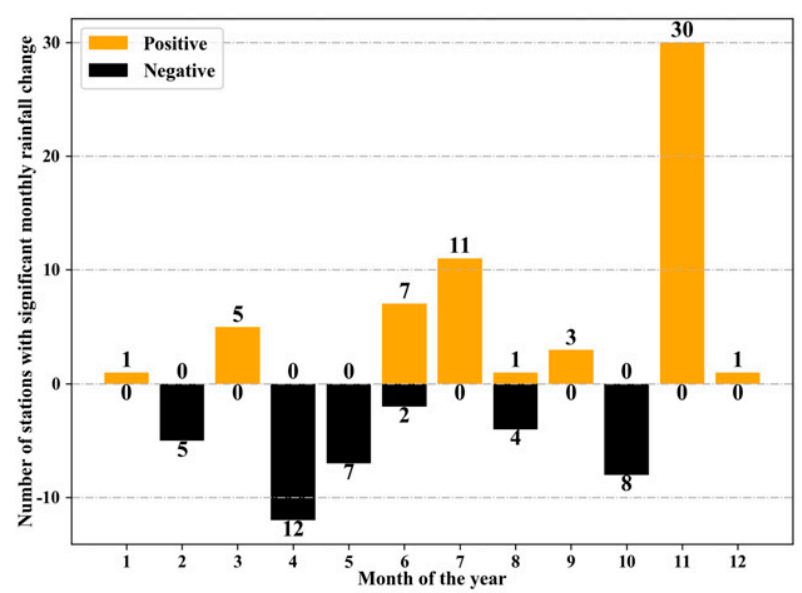

FIG. 4. The number of stations with significant monthly rainfall changes (at the $90 \%$ confidence level) in different months during 1967-2018.

basic meteorological stations in these two cities is also shown in Table 1.

\section{b. Characteristics of monthly rainfall}

Figure 3 presents the spatial distribution of the monthly average rainfall in SC during 1967-2018. There is usually little rain in SC from November to February, with average monthly rainfall between 20 and $85 \mathrm{~mm}$. More rainfall is observed from May to August in SC, with amounts ranging from 130 to $450 \mathrm{~mm}$. The month with the most rainfall is June, with rainfall values from 220 to $450 \mathrm{~mm}$. The area with rainfall exceeding $400 \mathrm{~mm}$ in June is almost the entire region. The average rainfall in the other months is approximately $55-260 \mathrm{~mm}$.

As seen from Fig. 3, the monthly average rainfall in the mainland area of the study region gradually decreases from the coastal areas to the inland during the months from July to September, and there are apparent high-value rainfall belts in the coastal areas. From November to March, the mainland's monthly average rainfall gradually increases from the coastal regions to the inland region. The monthly average rainfall distribution in May and June is similar to the annual average rainfall distribution (Fig. 2a). The monthly average rainfall in April gradually increases and that in October gradually decreases from the southwest to the northeast of the mainland. In contrast, the monthly rainfall pattern in Hainan Province shows different characteristics than that of the mainland. Similar to the annual rainfall distribution on Hainan Island (Fig. 2a), the monthly rainfall in the western region is generally lower than that in the eastern region.

Note that the monthly average rainfall on Hainan Island in September and October is significantly higher than that on the mainland. These two months are the wettest period for Hainan, indicating that the heavy rain in Hainan Province occurs later than that of the mainland.

\section{c. Trends in annual and monthly rainfall}

By using the Sen's slope and Mann-Kendall methods to analyze the annual and monthly rainfall series, it is found that
(a)Annual Guangzhou(113.48E, 23.22N)
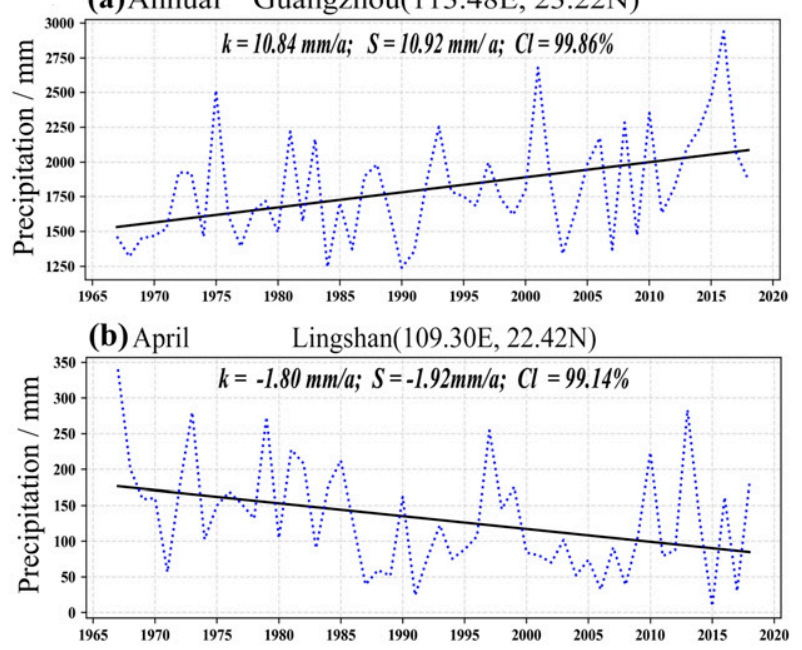

(c) November Shaoguan(113.60E, 24.67N)

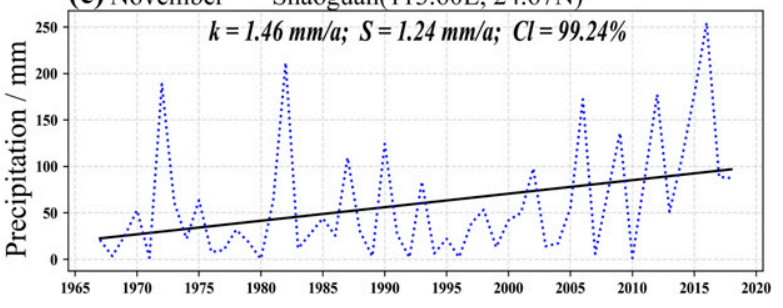

FIG. 5. Time series of the annual and monthly rainfall at some representative stations during 1967-2018: (a) for Guangzhou station, which has the most significant increasing trend in the annual rainfall; (b) for Lingshan station, which has the most significant decreasing trend in the monthly rainfall in April; and (c) for Shaoguan station, which has the most significant increasing trend in the monthly rainfall in November. In the figures, $k$ refers to the linear slope, with units of millimeters per year, $S$ refers to Sen's slope, and $\mathrm{Cl}$ refers to the confidence level. The blue dotted curve refers to the observed value, and the black solid line refers to the fitting trend.

five stations ( $8 \%$ of all stations) have significant positive trends for the annual rainfall during 1967-2018, which are illustrated by the purple upward triangles in Fig. 2a. No stations show significant decreasing annual rainfall, and these results are similar to the study by Gemmer et al. (2011). In particular, three of these stations are located in Hainan Province, illuminating a significant increase in the annual rainfall from 1967 to 2018, and the Sen's slopes of these stations' yearly rainfall with significant trends range from 4.70 to $10.92 \mathrm{~mm} \mathrm{yr}^{-1}$. The largest one occurs at Guangzhou station. In other words, the yearly rainfall at Guangzhou station increased at a rate of $10.92 \mathrm{~mm} \mathrm{yr}^{-1}$ in the

TABLE 2. The variance contribution and the cumulative variance contribution of the six principal EOFs.

\begin{tabular}{lccrrrr}
\hline \hline \multicolumn{1}{c}{ EOFs } & EOF1 & EOF2 & EOF3 & EOF4 & EOF5 & EOF6 \\
\hline Contribution (\%) & 60.1 & 11.4 & 4.2 & 3.9 & 2.3 & 1.7 \\
Accumulation(\%) & 60.1 & 71.5 & 75.7 & 79.6 & 81.9 & 83.6 \\
\hline
\end{tabular}


(a)

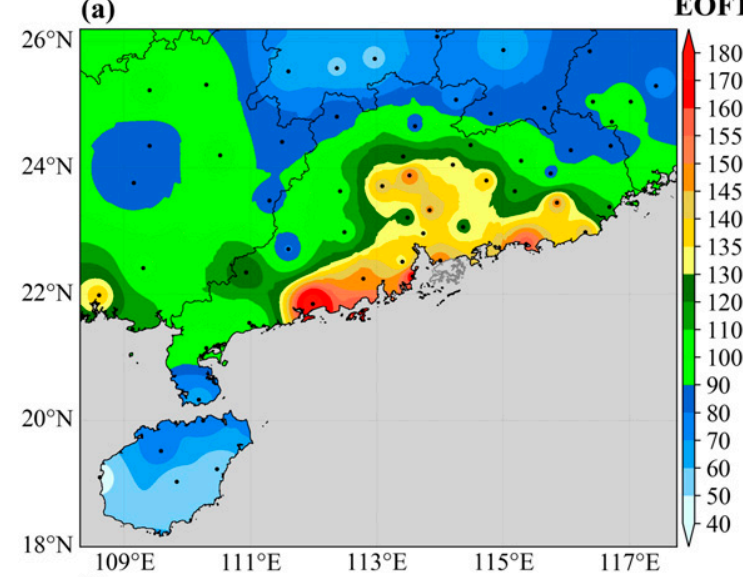

(c)
EOF1(60.09\%)

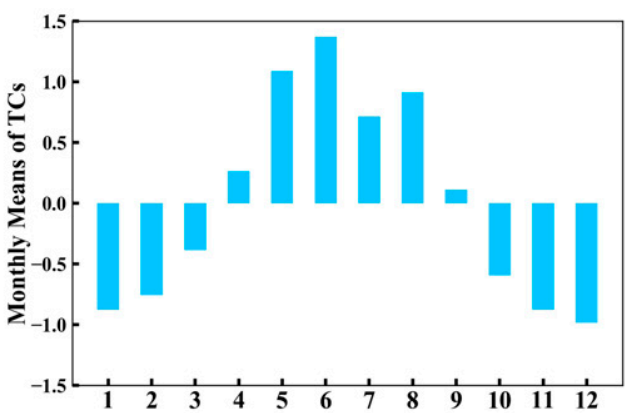

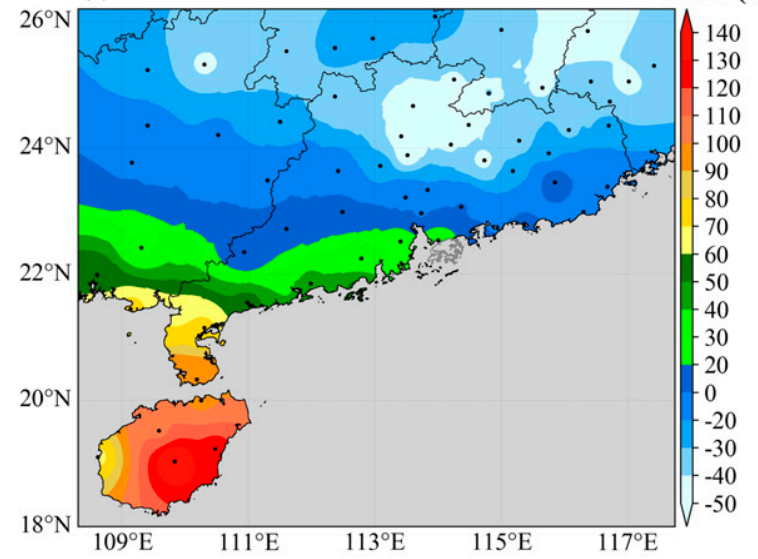

(d)

FIG. 6. (left) The spatial rainfall distributions and (right) the mean time coefficients of the 12 months for (a),(b) EOF1 and (c),(d) EOF2.

past 52 years. If Guangzhou's rain continues to grow at the same rate, this area will be very vulnerable to floods and landslides in the future.

For the trend analysis of the monthly rainfall series in SC, each month shows different change patterns. The purple upward triangles denote the stations with significantly increasing monthly rainfall, and the black downward triangles indicate the stations with significantly decreasing monthly rainfall in Fig. 3. Figure 4 summarizes the number of stations with significant rainfall changes in different months. It can be seen from Figs. 3 and 4 that November is the month with the most stations having significant positive trends in monthly rainfall, while April is the month with the most stations having significant negative trends in monthly rainfall. There are 30 (48\%) stations in November showing a significant increasing trend in monthly rainfall during 1967-2018, which are mainly distributed in the Guangdong region of $111^{\circ}-115^{\circ} \mathrm{E}$, and the range of Sen's slope value for the significant change in rainfall is [0.27, 1.24] $\mathrm{mm} \mathrm{yr}^{-1}$. In April, 12 (19\%) stations showed a significant decreasing trend in monthly rainfall during 1967-2018. They are mainly distributed in Guangxi Province with longitudes from $109^{\circ}$ to $111^{\circ} \mathrm{E}$, and the range of Sen's slope value for significant rainfall changes is $[-1.92,-0.91] \mathrm{mm} \mathrm{yr}^{-1}$. It is worth mentioning that the stations in the coastal areas, which usually have high annual rainfall (Fig. 2a), hardly show a significant change trend in monthly precipitation during the flooding season, except in July.

The trends of monthly rainfall analyzed above are very different from the investigation of the rainfall change in the Zhujiang River basin by Gemmer et al. (2011). According to their paper, for the areas overlapping with this study, they found that the monthly rainfall in October has a significant decreasing trend at most stations. However, there are fewer stations with significant decreases in October in this study. November is the month with the largest number of stations with significant increases in monthly rainfall in this study (Fig. 4), while in their study, there is no significant increase at stations in November. These differences may be due to their different period of analysis. The period analyzed in the study by Gemmer et al. (2011) is from 1961 to 2007, which is different from this study period. If we analyze the data from 1967 to 2007, we can obtain similar results in October and November when compared with the analysis by Gemmer et al. (2011). Figure 5 shows the time series of the annual rainfall and monthly rainfall at some representative stations. Figure 5a shows the time series of annual rainfall at Guangzhou station, which 
has the most significant yearly rainfall increasing trend. Figure $5 \mathrm{~b}$ shows the time series of the monthly rainfall at Lingshan station in April, which has the most significant monthly rainfall decreasing trend, while Fig. 5c shows the time series of the monthly rainfall at Shaoguan in November, which has the most significant monthly rainfall increasing trend.

\section{d. Dominant patterns of monthly rainfall in $S C$}

Through EOF analysis of the monthly rainfall anomaly for the 63 stations in SC during 1967-2018, the variance contribution and the cumulative variance contribution rate of each pattern are obtained (Table 2). Table 2 shows that the first four EOFs explain almost $80 \%$ of the total variation. In particular, the eigenvalues of the corresponding patterns pass the North's assessment (North et al. 1982; Hannachi et al. 2007), which indicates that the first four EOFs represent the major patterns of the monthly rainfall in SC, and each pattern is independently separable.

The variance contribution of EOF1 reaches $60.09 \%$, and it interprets the primary information of the monthly rainfall in SC. EOF1 (Fig. 6a) shows a straw hat-shaped region with high rainfall formed in the central and coastal areas of Guangdong Province. The modal values for EOF1 (Fig. 6a) are uniformly positive, which indicates that the rainfall for the first mode in $\mathrm{SC}$ is synchronously higher or lower than the monthly rainfall average value over the 52 years. The monthly means of TCs for EOF1 from April to September are positive, with the maximum value occurring in June, indicating that June is usually the rainiest month and April to September represent the rainy season in this area. From October to March, the monthly means of TCs for EOF1 are negative, indicating that the spatial distribution for these months is opposite to Fig. 6a, and these months represent the dry season.

The variance contribution of EOF2 is $11.41 \%$, and it shows that the value over the area south and north of the Tropic of Cancer is respectively positive and negative. Moreover, the value variation over the area south of the Tropic of Cancer is more intense than that over the northern area in Fig. 6c. For the monthly mean TCs of EOF2, the positive extreme coefficient is in September and the negative extreme coefficient is in March. Combined with Fig. 3, it can be seen that the spatial distribution of monthly rainfall monitored via NBMSs is similar to EOF2, where there are extreme differences between the northern and southern parts of the study region in September and March (Fig. 3). Note that the correlation between the grid values for EOF2 and their latitudes in March and September is 0.93 and -0.93 , respectively, which indicates that the second spatial rainfall pattern is highly correlated with latitude. In addition, the maximum value of the power spectrum for EOF1 and EOF2 appears at 12 via harmonic analysis, indicating that there is a yearly variation period for the first two modes.

As can be seen from Figs. 3 and 4, April and November are two months with the most stations showing significant decreasing and increasing rainfall change. Therefore, the TCs corresponding to EOF1 in April and November for the study period are further explored. It can be seen from Fig. 7a that there exists an insignificant decreasing rainfall trend in April from 1967 to 2018. And there exists a significant increasing

\section{(a)}
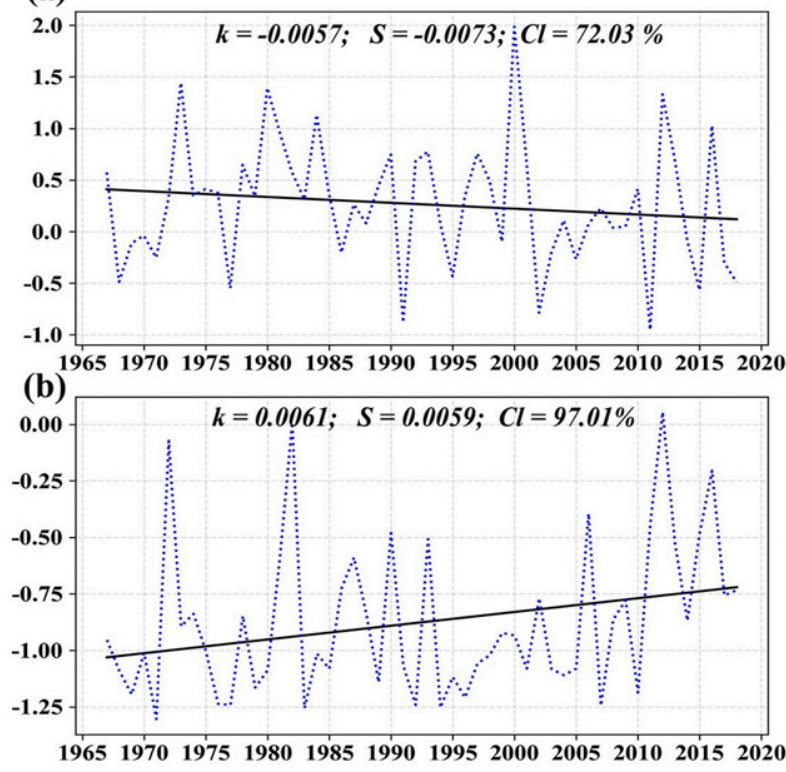

FIG. 7. The time coefficients corresponding to the EOF1 in (a) April and (b) November. The labeling information is as in Fig. 5.

rainfall trend in November for the study period (Fig. 7b), which is in agreement with the results of the monthly rainfall trend analysis shown in Figs. 3 and 4.

\section{The analysis of environmental background}

Many environmental factors are believed to have effects on the spatial and temporal rainfall distribution in SC, such as the Pacific Ocean SST, geographical location, monsoon system, large-scale circulation of horizontal wind, geopotential height, and moisture. However, the most immediate and fundamental factor is moisture circulation (Ding 1992; Ding and Chan 2005; Zhang et al. 2008; Gemmer et al. 2011; Wang et al. 2015; Yao et al. 2016; Gu et al. 2018). Therefore, this paper explores how moisture circulation influences precipitation in SC via the characteristics of VIMF and VIMFD.

As shown in Fig. 8, the cold and weak moisture from the northeast causes convergence in the northeastern area of SC and strong divergence in the southwest in winter (from December to February). Therefore, the SC area has less precipitation during this season, and the rainfall distribution is more in the north and less in the south.

In spring, it can be seen from Fig. 8 that the moisture from the northeastern mainland gradually weakens, and the southwestern moisture becomes stronger with the arrival of the first flooding season (April-June) in SC. The southwestern water vapor in $\mathrm{SC}$ is formed by eastern wind moisture transport from south of the western Pacific subtropical high, but it diverts into SC from the South China Sea and Indochina Peninsula (Chi et al. 2005; Chow et al. 2008). In spring, the interaction between cold air from the mainland and warm ocean flow will generally result in precipitation over the region. In addition, with the 

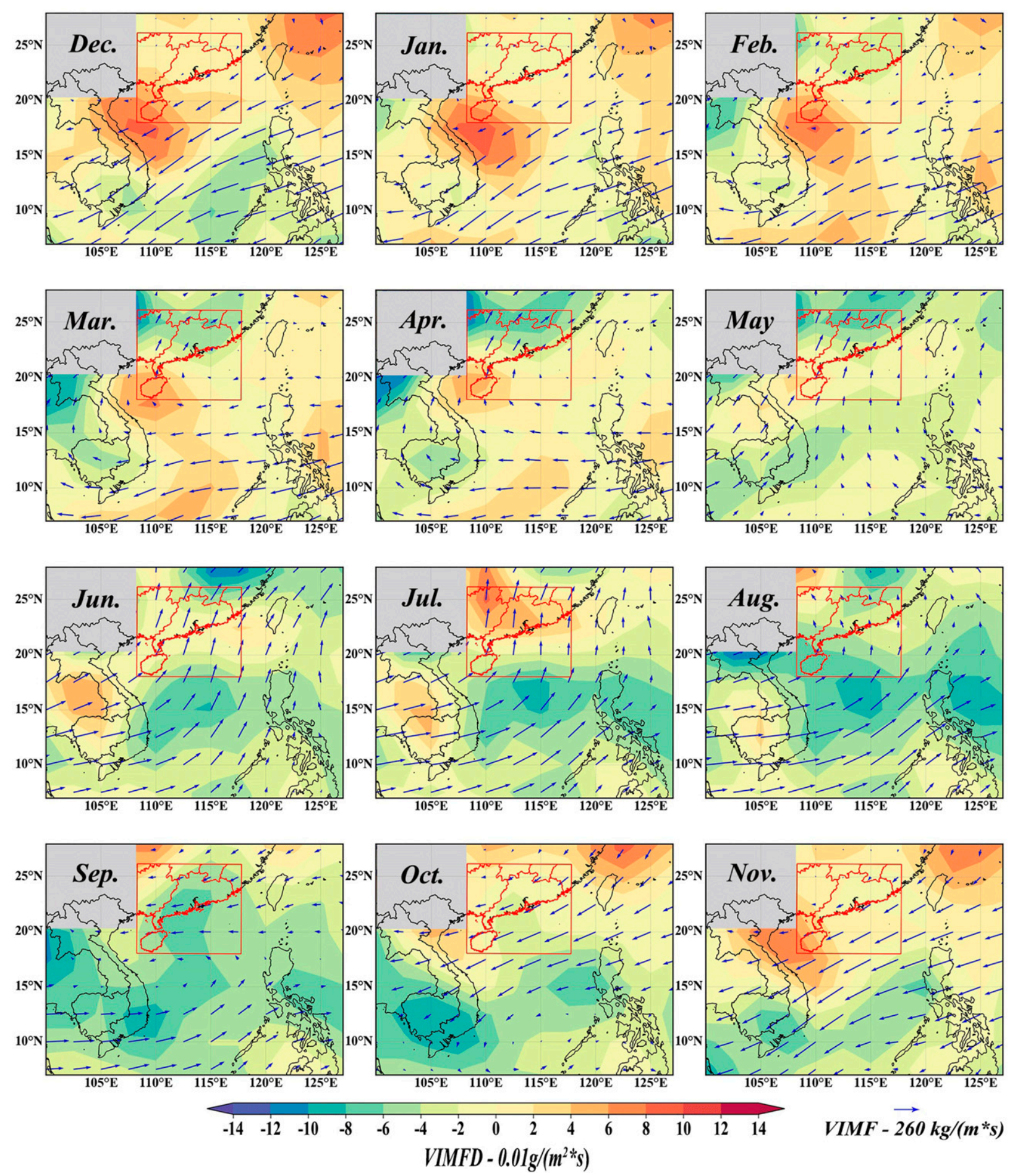

FIG. 8. The average monthly VIMF (vectors) and VIMFD (shading) from 1000 to $700 \mathrm{hPa}$ during 1967-2018.

onset of the South China Sea summer monsoon, the gradual formation of the new southwestern moisture stream from the Bay of Bengal causes more rainfall in May (Zeng et al. 2005; Chi et al. 2005). Figure 8 indicates that the moisture convergence region in SC expands from March to May.
The East Asian summer monsoon and the Indian summer monsoon are the two essential components of the Asian summer monsoon (Ding and Chan 2005; Chow et al. 2008). With their onset, the southwestern moisture flow and the South China Sea moisture flow begin to provide sufficient water vapor during 


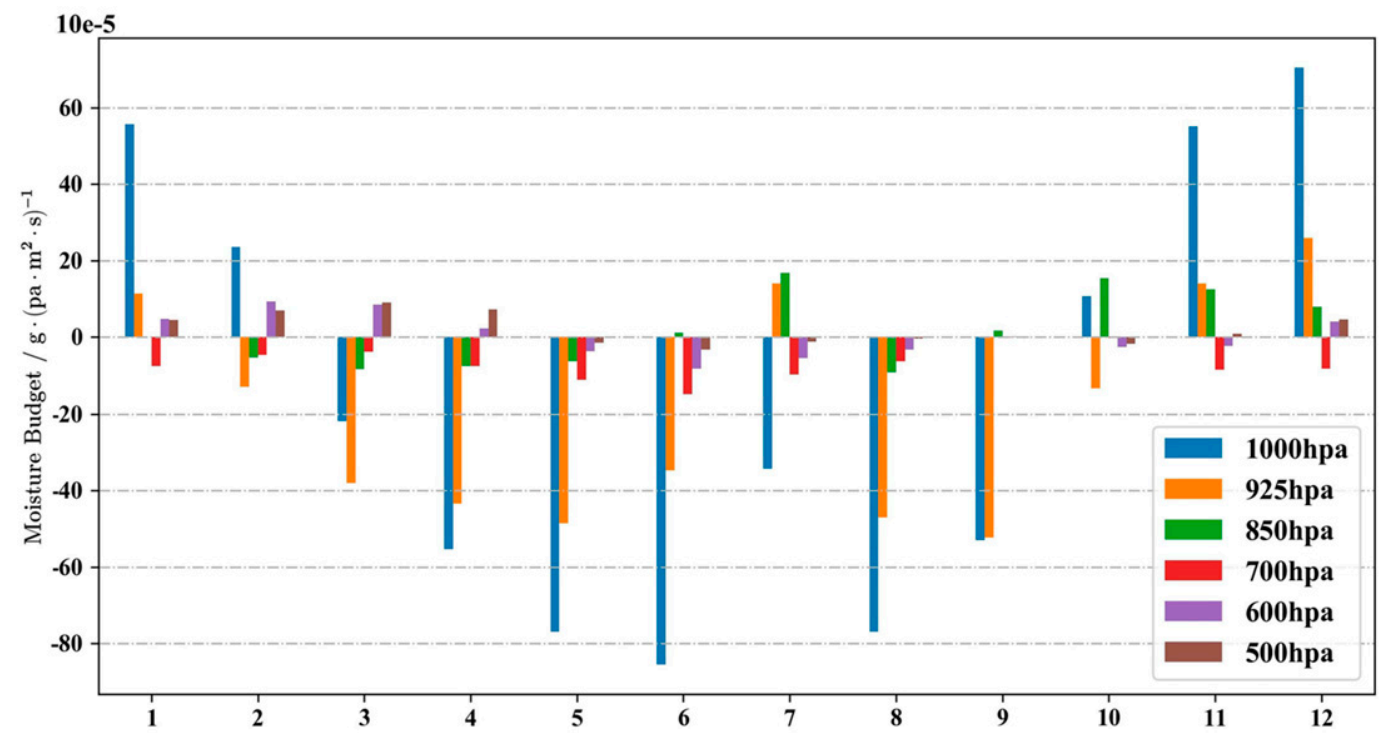

FIG. 9. The mean monthly moisture budget in South China at different atmospheric levels from 1967 to 2018.

summer in SC (Tian et al. 2004; Chow et al. 2008; Chu et al. 2019). Figure 8 shows that the water vapor transport in summer is significantly higher than that in any other season (Fig. 8), and this strong water vapor transport leads to abundant rainfall over the area in summer. As revealed by Tian et al. (2004), the greater is the moisture transport from the South China Sea, the more precipitation will be in SC. However, there is a contradiction between the strong moisture divergence in July in SC (Fig. 8) and the July rainfall observation (Fig. 3). Therefore, the total moisture budget at each layer of each month in SC is calculated (Fig. 9). Strong moisture divergence occurs at $850 \mathrm{hPa}$ in July; however, there is high water vapor convergence at $1000 \mathrm{hPa}$. Therefore, the moisture flux divergence distribution from 1000 to $925 \mathrm{hPa}$ for the summertime is shown (Fig. 10). In comparison with the entire VIMFD layer, the moisture flux divergence distribution of the bottom layer is more consistent with the actual observed rainfall distribution during summer in SC.

In autumn, the moisture from the southwest and the South China Sea decreases, but the airflow from the northeastern mainland, which is cold and dry, and the subtropical western Pacific (Li et al. 2010) gradually increases (Fig. 8), leading to the decreased rainfall in SC. In September, cyclonic circulation, which originates from the Indian Ocean through the Bay of Bengal, occurs over the South China Sea. This results in moisture convergence in the coastal areas of SC and Hainan Province (Fig. 8), leading to more rainfall in the corresponding regions than inland SC. Moreover, the rainfall in September and October over the study area may be affected by tropical cyclones.

The analysis in section $4 \mathrm{c}$ shows that November is the month with the most stations having significant positive trends in
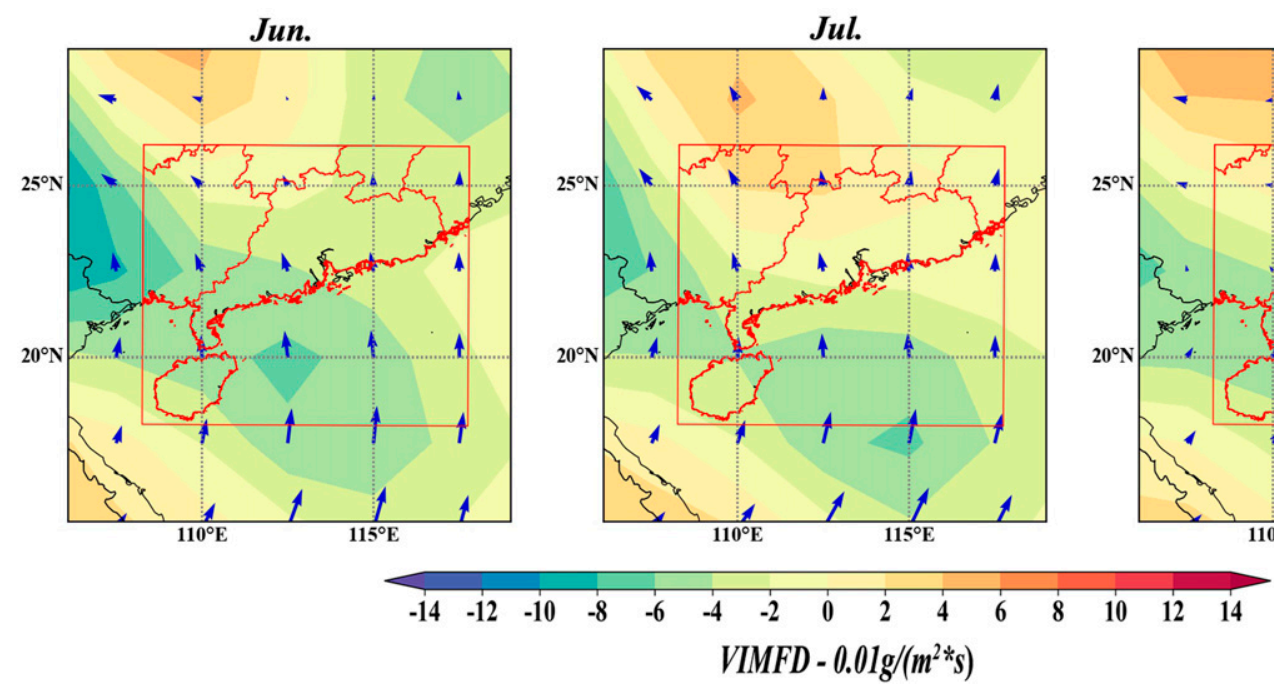

Aug.

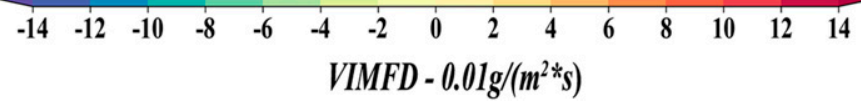

$V I M F-260 \mathrm{~kg} /(\mathrm{m} * \mathrm{~s})$

FIG. 10. The moisture flux divergence distribution from 1000 to $925 \mathrm{hPa}$ in South China for summertime from 1967 to 2018. 
(a) Apr.

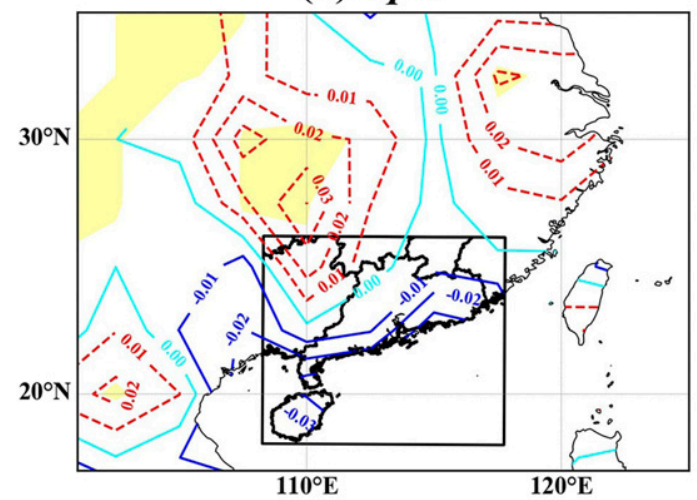

(b) Nov.

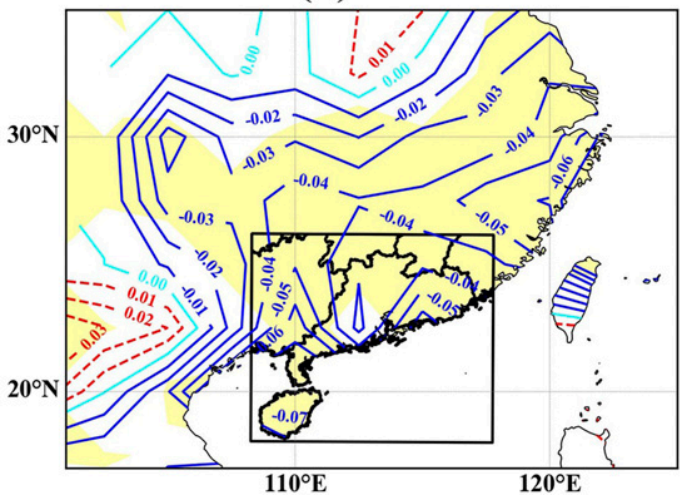

FIG. 11. The trends of the monthly moisture flux divergence in April and November from 1967 to 2018 in South China (marked by the black-outlined rectangle). The contour lines represent the Sen's slope values of the trends, with the red dashed lines referring to positive trends, blue solid lines referring to negative trends, and cyan solid lines referring to 0 . The yellow-shaded area indicates that the trend values are significant at the $90 \%$ confidence level.

monthly rainfall, whereas April is the month with the most stations having significant negative trends in monthly rainfall. To explore the possible physical mechanism for these trends, we analyze the trend of the monthly moisture flux divergence in April and November from 1967 to 2018 (Fig. 11). If the regional moisture divergence decreases, the regional moisture convergence will increase, which will generally lead to an increase in precipitation over the area. On the other hand, if the moisture flux divergence increases, precipitation will generally decrease. The moisture flux divergence in most parts of SC has a significant downward trend in November (Fig. 11b), which can explain why the precipitation at $30(48 \%)$ stations over the study area in November increases significantly (Fig. 3). In April, there is no significant trend of moisture flux divergence in the study area (Fig. 11a). In northern Guangxi Province, the moisture flux divergence increases insignificantly. This may explain why only 12 stations (19\%) have a significant decrease in the monthly rainfall in the area (Fig. 3).

\section{Conclusions}

This study uses meteorological observation data from 1967 to 2018 to analyze the spatiotemporal rainfall distribution characteristics in SC. There are few stations with significant annual rainfall changes. The average yearly rainfall in SC gradually decreases from the coastal area to inland. However, the average annual rainy days gradually increase from coastal regions to inland, resulting in a larger precipitation intensity in coastal regions than that in inland areas.

Monthly rainfall showed the most significant decreasing and increasing trend in April and November, respectively. The significant monthly rainfall changes are due to the moisture flux changes in the study area from 1967 to 2018. The spatial distribution of monthly rainfall is different in different seasons. In winter, the cold moisture of the northeastern mainland caused the precipitation to decrease from the inland to the coast. The interaction of cold air originating from North China and warm ocean airflow coming from the western Pacific subtropical high leads to the high-value rainfall belt moving southward in spring. In summer, with the onset of the East Asian summer monsoon and the Indian summer monsoon, a steady stream of water vapor delivery has brought abundant precipitation to SC. In autumn, with the closure of the water vapor path in summer, rainfall in various parts of SC gradually decreases. However, Hainan Island still has heavy rain convergence because of tropical cyclones affecting the region. In addition, the spatial distribution of precipitation in SC during summer is more consistent with the moisture flux divergence distribution of the bottom layer from 925 to $1000 \mathrm{hPa}$ than the layer from 700 to $1000 \mathrm{hPa}$.

The dominant pattern of the monthly rainfall variation in $\mathrm{SC}$ is mainly the annual cycle, and the spatial variance contributions of EOF1 and EOF2 are $60.09 \%$ and $11.41 \%$, respectively. The spatial distribution of EOF1 is similar to the annual average rainfall and represents the precipitation pattern of the flooding season, which is caused by various synoptic systems. The EOF2 descends from south to north. The area south of the Tropic of Cancer is positive and the area north of it is negative, which may be associated with the East Asian monsoon.

Acknowledgments. This study was supported by the Science and Technology Department of Guangdong Province with Grant 2019B111101002 and the Innovation of Science and Technology Commission of Shenzhen Municipality Ministry with Grant JCYJ20180305180905450.

\section{REFERENCES}

Becker, S., M. Gemmer, and T. Jiang, 2006: Spatiotemporal analysis of precipitation trends in the Yangtze River catchment. Stochastic Environ. Res. Risk Assess., 20, 435-444, https:// doi.org/10.1007/s00477-006-0036-7.

Beniston, M., and D. B. Stephenson, 2004: Extreme climatic events and their evolution under changing climatic conditions. 
Global Planet. Change, 44, 1-9, https://doi.org/10.1016/ j.gloplacha.2004.06.001.

Chi, Y., J. He, and Z. Wu, 2005: Features analysis of the different precipitation periods in the pre-flood season in South China (in Chinese). J. Nanjing Inst. Meteor., 28, 163-171.

Chow, K. C., H. W. Tong, and J. C. L. Chan, 2008: Water vapor sources associated with the early summer precipitation over China. Climate Dyn., 30, 497-517, https://doi.org/10.1007/ s00382-007-0301-6.

Chu, Q. C., R. Zhi, Q. G. Wang, and G. L. Feng, 2019: Roles of moisture sources and transport in precipitation variabilities during boreal summer over East China. Climate Dyn., 53, 5437-5457, https://doi.org/10.1007/s00382-019-04877-z.

Ding, Y., 1992: Summer monsoon rainfalls in China. J. Meteor. Soc. Japan, 70, 373-396, https://doi.org/10.2151/jmsj1965.70.1B_ 373.

— An overview. Meteor. Atmos. Phys., 89 (1-4), 117-142, https:// doi.org/10.1007/s00703-005-0125-z.

— , G. Ren, G. Shi, P. Gong, X. Zheng, and P. Zhai, 2007: China's National Assessment Report on Climate Change (I): Climate change in China and the future trend. Adv. Climate Change Res., 3 (Suppl.), 1-5.

— Z. Zang, and Y. Sun, 2008: Inter-decadal variation of the summer precipitation in East China and its association with decreasing Asian summer monsoon. Part I: Observed evidences. Int. J. Climatol., 28, 1139-1161, https://doi.org/10.1002/ joc. 1615.

Dore, M. H., 2005: Climate change and changes in global precipitation patterns: What do we know? Environ. Int., 31, 11671181, https://doi.org/10.1016/j.envint.2005.03.004.

Feng, S., Q. Hu, and W. Qian, 2004: Quality control of daily meteorological data in China, 1951-2000: A new dataset. Int. J. Climatol., 24, 853-870, https://doi.org/10.1002/joc.1047.

Fischer, T., M. Gemmer, L. Liu, and B. Su, 2011: Change-points in climate extremes in the Zhujiang River Basin, South China, 1961-2007. Climatic Change, 110, 783-799, https://doi.org/ 10.1007/s10584-011-0123-8.

Gemmer, M., S. Becker, and T. Jiang, 2004: Observed monthly precipitation trends in China 1951-2002. Theor. Appl. Climatol., 77, 39-45, https://doi.org/10.1007/s00704-003-0018-3.

- , T. Fischer, T. Jiang, B. Su, and L. L. Liu, 2011: Trends in precipitation extremes in the Zhujiang River basin, South China. J. Climate, 24, 750-761, https://doi.org/10.1175/ 2010JCLI3717.1.

Gocic, M., and S. Trajkovic, 2013: Analysis of changes in meteorological variables using Mann-Kendall and Sen's slope estimator statistical tests in Serbia. Global Planet. Change, 100, 172-182, https://doi.org/10.1016/j.gloplacha.2012.10.014.

Goovaerts, P., 2000: Geostatistical approaches for incorporating elevation into the spatial interpolation of rainfall. J. Hydrol., 228, 113-129, https://doi.org/10.1016/S0022-1694(00)00144-X.

Gu, W., L. Wang, Z. Z. Hu, K. Hu, and Y. Li, 2018: Interannual variations of the first rainy season precipitation over South China. J. Climate, 31, 623-640, https://doi.org/10.1175/JCLID-17-0284.1.

Hannachi, A., I. T. Jolliffe, and D. B. Stephenson, 2007: Empirical orthogonal functions and related techniques in atmospheric science: A review. Int. J. Climatol., 27, 1119-1152, https:// doi.org/10.1002/joc.1499.

Jiang, Z., D. L. Zhang, R. Xia, and T. Qian, 2017: Diurnal variations of presummer rainfall over southern China. J. Climate, 30, 755-773, https://doi.org/10.1175/JCLI-D-15-0666.1.
Kalnay, E., and Coauthors, 1996: The NCEP/NCAR 40-Year Reanalysis Project. Bull. Amer. Meteor. Soc., 77, 437-471, https:// doi.org/10.1175/1520-0477(1996)077<0437:TNYRP>2.0.CO;2.

Kirkyla, K. I., and S. Hameed, 1989: Harmonic analysis of the seasonal cycle in precipitation over the United States: A comparison between observations and a general circulation model. J. Climate, 2, 1463-1475, https://doi.org/10.1175/15200442(1989)002<1463:HAOTSC > 2.0.CO;2.

Labat, D., Y. Goddéris, J. L. Probst, and J. L. Guyot, 2004: Evidence for global runoff increase related to climate warming. Adv. Water Resour., 27, 631-642, https://doi.org/10.1016/ j.advwatres.2004.02.020.

Li, X., W. Liang, and Z. Wen, 2010: Characteristics of the atmospheric water vapor and its relationship with rainfall in South China in northern autumn, winter and spring (in Chinese). J. Trop. Meteor., 26, 626-632.

Liu, C., 2004: The issues in the impact study of climate change on the terrestrial hydrological cycle (in Chinese). Adv. Earth Sci., 19, 115-119.

Liu, D., S. Guo, X. Chen, and Q. Shao, 2012: Analysis of trends of annual and seasonal precipitation from 1956 to 2000 in Guangdong Province, China. Hydrol. Sci. J., 57, 358-369, https://doi.org/10.1080/02626667.2011.636748.

Liu, L., T. Jiang, and F. Yuan, 2009: Observed (1961-2007) and projected (2011-2060) climate change in the Pearl River Basin (in Chinese). Adv. Climate Change Res., 5, 209-214.

Liu, Q., Z. Yang, and B. Cui, 2008: Spatial and temporal variability of annual precipitation during 1961-2006 in Yellow River Basin, China. J. Hydrol., 361, 330-338, https://doi.org/10.1016/ j.jhydrol.2008.08.002.

Lorenz, E. N., 1956: Empirical orthogonal functions and statistical weather prediction. Massachusetts Institute of Technology Department of Meteorology Statistical Forecast Project Rep. 1, 49 pp., http://www.o3d.org/abracco/Atlantic/Lorenz1956.pdf.

Lu, X., Q. Li, S. Chen, K. Zhang, L. Sun, Q. Chen, and L. Zhang, 2019: Temporal and spatial precipitation characteristics in Shenzhen from 2008 to 2017 (in Chinese). Adv. Meteor. Sci. Technol., 9, 171-178.

Luo, Y., S. Liu, S. Fu, J. Liu, G. Wang, and G. Zhou, 2008: Trends of precipitation in Beijiang River Basin, Guangdong Province, China. Hydrol. Processes, 22, 2377-2386, https://doi.org/10.1002/ hyp.6801.

Lyons, S. W., 1982: Empirical orthogonal function analysis of Hawaiian rainfall. J. Appl. Meteor. Climatol., 21, 17131729, https://doi.org/10.1175/1520-0450(1982)021<1713: $\mathrm{EOFAOH}>2.0 . \mathrm{CO} ; 2$.

Mirza, M. M. Q., 2002: Global warming and changes in the probability of occurrence of floods in Bangladesh and implications. Global Environ. Change, 12, 127-138, https://doi.org/10.1016/ S0959-3780(02)00002-X.

National Meteorological Information Center, 2019: China meteorological dataset. China Meteorological Administration, accessed 14 February 2019, http://data.cma.cn.

Ning, L., and Y. Qian, 2009: Interdecadal change in extreme precipitation over South China and its mechanism. Adv. Atmos. Sci., 26, 109-118, https://doi.org/10.1007/s00376-009-0109-x.

North, G. R., T. L. Bell, R. F. Cahalan, and F. J. Moeng, 1982: Sampling errors in the estimation of empirical orthogonal functions. Mon. Wea. Rev., 110, 699-706, https://doi.org/ 10.1175/1520-0493(1982)110<0699:SEITEO > 2.0.CO;2.

Oguntunde, P. G., J. Friesen, N. van de Giesen, and H. H. G. Savenije, 2006: Hydroclimatology of the Volta River Basin in West Africa: Trends and variability from 1901 to 2002. 
Phys. Chem. Earth, 31, 1180-1188, https://doi.org/10.1016/ j.pce.2006.02.062.

Qian, W., and X. Lin, 2005: Regional trends in recent precipitation indices in China. Meteor. Atmos. Phys., 90, 193-207, https:// doi.org/10.1007/s00703-004-0101-z.

Sayemuzzaman, M., and M. K. Jha, 2014: Seasonal and annual precipitation time series trend analysis in North Carolina, United States. Atmos. Res., 137, 183-194, https://doi.org/ 10.1016/j.atmosres.2013.10.012.

Sen, P. K., 1968: Estimates of the regression coefficient based on Kendall's tau. J. Amer. Stat. Assoc., 63, 1379-1389, https:// doi.org/10.1080/01621459.1968.10480934.

Sun, R., Z. Wu, B. Chen, G. Lan, and D. Qi, 2017: Change features of precipitation events in Hainan Island from 1959 to 2013 (in Chinese). Chin. J. Trop. Crops, 38, 2176-2182.

Tian, H., P. Guo, and W. Lu, 2004: Characteristics of vapor inflow corridors related to summer rainfall in China and impact factors (in Chinese). J. Trop. Meteor., 20, 401-408.

van Zomeren, J., and A. van Delden, 2007: Vertically integrated moisture flux convergence as a predictor of thunderstorms. Atmos. Res., 83, 435-445, https://doi.org/10.1016/j.atmosres.2005.08.015.

Wang, X., W. Jiang, Y. Deng, and Z. Jiang, 2019: Hourly rainfall dynamics and hazard dynamic assessment of Mangkhut Typhoon-affected areas (in Chinese). J. Catastrophology, 34, 202-208.

Wang, Y., X. Chen, and F. Yan, 2015: Spatial and temporal variations of annual precipitation during 1960-2010 in China. Quat. Int., 380-381, 5-13, https://doi.org/10.1016/j.quaint.2014.12.047.

Yang, F., and K. M. Lau, 2004: Trend and variability of China precipitation in spring and summer: Linkage to sea-surface temperatures. Int. J. Climatol., 24, 1625-1644, https://doi.org/ 10.1002/joc.1094.
Yao, S., Q. Huang, and C. Zhao, 2016: Variation characteristics of rainfall in the pre-flood season of South China and its correlation with sea surface temperature of Pacific. Atmosphere, 7, 5, https://doi.org/10.3390/atmos7010005.

Yue, S., and C. Wang, 2002: Applicability of prewhitening to eliminate the influence of serial correlation on the MannKendall test. Water Resour. Res., 38, 1068, https://doi.org/ 10.1029/2001WR000861.

Zeng, Q. C., D. L. Zhang, M. Zhang, R. T. Zuo, and J. X. He, 2005: The abrupt seasonal transitions in the atmospheric general circulation and the onset of monsoons part I: Basic theoretical method and its application to the analysis of climatological mean observations (in Chinese). Climatic Environ. Res., 10, 285-302, https://doi.org/10.3878/j.issn.10069585.2005.03.03.

Zhang, Q., T. Jiang, M. Gemmer, and S. Becker, 2005: Precipitation, temperature and runoff analysis from 1950 to 2002 in the Yangtze basin, China. Hydrol. Sci. J., 50, 65-80, https://doi.org/ 10.1623/hysj.50.1.65.56338.

- C. Y. Xu, Z. Zhang, Y. D. Chen, C. Liu, and H. Lin, 2008: Spatial and temporal variability of precipitation maxima during 1960-2005 in the Yangtze River Basin and possible association with large-scale circulation. J. Hydrol., 353, 215227, https://doi.org/10.1016/j.jhydrol.2007.11.023.

$\longrightarrow,-$ Z Z. X. Zhang, Y. D. Chen, and C. L. Liu, 2009a: Spatial and temporal variability of precipitation over China, 19512005. Theor. Appl. Climatol., 95, 53-68, https://doi.org/10.1007/ s00704-007-0375-4.

, - - S. Becker, Z. X. Zhang, Y. D. Chen, and M. Coulibaly, 2009b: Trends and abrupt changes of precipitation maxima in the Pearl River Basin, China. Atmos. Sci. Lett., 10, 132-144, https://doi.org/10.1002/asl.221. 